worthy of note. Lick Observatory Bulletin No. 54 gives elliptic elements computed by Messrs. Curtiss and Albrecht. The extraordinarily small eccentricity (0.17733) together with the major axis $(\log a=0.31970)$ at once suggests asteroidal orbits. In fact, so far as size is concerned, the orbit is seen to lie between the orbits of Mars and Jupiter, the comet's perihelion distance being slightly greater than the aphelion distance of Mars. It will also be noticed that the eccentricity is less than that of Mercury's orbit, and, indeed, less than the eccentricities of the orbits of many of the minor planets, including Eros. But the inclination, more than $126,^{\circ}$ with consequent retrograde motion, of course sharply distinguishes it from any known planetary orbit.

However disappointing the comet may be in its physical appearance and characteristics, it is to be hoped that a number of observations may be secured and a study of the orbit made, with especial reference to the comet's past and future relations to Mars and Jupiter when in or near its line of nodes.

Ellen Hayes.
Whitin OBSERVATORY, WeLlesley, Mass., May 4, 1904.

\section{SPECIAL ARTICLES.}

THE WATER-SOLUble PLANT FOOD OF SOILs.*

Data were given showing the amount of phosphoric acid removed by crops, particularly wheat, at different stages of growth. In the case of wheat it was shown that from one square yard of soil 1,106 grams of dry matter, containing 10.18 grams of phosphoric acid, were secured. Does all of this come from water soluble forms? Reference was made to Hellriegel's exhaustive work, showing that 359 grams of water are required to produce one gram of dry matter in the form of spring wheat. It was found that the quantity of water required to produce 1,106 grams of wheat could dissolve only 1.9 grams of phosphoric acid from the soil upon which the wheat was

* Presented at the St. Louis (1903) meeting of the Society for the Promotion of Agricultural Science. grown. In determining the water soluble phosphoric acid the quantities of soil and water recommended by Whitney and Cameron in Bulletin No. 22, Division of Soils, U. S. Department of Agriculture, were used. The soil was left in contact with the water for fifteen days.

It was shown that if all the water taken from the soil was in the form of a saturated soil solution by physical action alone only 1.9 grams could have been supplied out of a total of 10.18 grams, in water-soluble forms. The conclusion was reached that over 81 per cent. of the phosphoric acid of the wheat crop was secured from forms insoluble in water. Similar data for oats, peas, corn and flax showed that the water-soluble phosphoric acid was only a minor factor in the food supply of the crops.

Some of the data in Bulletin No. 22 were examined. The experiments by Birner and Lucanus were reviewed, and it was shown that all of the data were not given. Instead of being a normal oat crop, as claimed by Whitney and Cameron, it was shown that Birner and Lucanus secured from three to six times as much organic matter when more plant food than that secured in the well water was supplied. There were abnormal amounts of plant food, particularly nitrates, in the well water; over sixty parts per million were present. This was shown to be more than is found in London sewage. The work of Birner and Lucanus can not be questioned, but the application of their results was shown to be inconsistent. It was noted on one page (10) that 'with the chemical methods then available it was realized that the small amount of plant food contained in a soil extract could not be determined with sufficient accuracy to justify the formation of any definite conclusion,' and then on a subsequent page the results of Birner and Lucanus, obtained in 1863-1866, by such methods, are cited as the only evidence that plants obtain all of their food from water-soluble forms.

The action of plant roots upon limestone is accounted for by Whitney and Cameron by the soil water being charged with carbon dioxide. It has been shown that the same result was secured when most seeds were germi- 
nated between litmus paper moistened with distilled water. The acid tracings of the roots were distinct, and there were no soil solutions charged with carbon dioxide present.

A critical examination of the data given in Bulletin No. 22 shows that the conclusion is not consistent, with the figures. To illustrate: On page 32 it is stated that a wheat field yielding 35 bushels per acre contained 2.49 parts of $\mathrm{PO}_{4}$ per million parts of air-dry soil. The most liberal calculations show less than five pounds per acre foot of water-soluble phosphoric acid; accepting the data given as correct, a wheat crop of 35 bushels would remove 40 pounds at least of phosphoric acid. In other words, all of the water-soluble phosphoric acid in this soil to a depth of eight feet by pure physical action alone would not supply this crop with food. To assume that all the water-soluble plant food can possibly be utilized to a depth of eight feet is even an incorrect assumption, because Hellriegel's experiments show conclusively that there is a limit to the capacity of crops for absorbing water.

To assume that a selective process takes place based on physical properties alone and that the plant has the power to take up more water-soluble phosphoric acid than water in which it is dissolved independent of chemical action or solvent power is not correct. Because if such a purely physical action were to take place, the ions of lime, magnesia, etc., forced back into the solution by the withdrawal of the $\mathrm{PO}_{4}$, ions would make the remaining phosphoric acid less soluble. In fact, purely physical action based upon ionization, as claimed by the authors, would be working against the plant instead of aiding it in securing plant food.

Most of the data given in Bulletin No. 22 point to just the opposite conclusions from those drawn. It is stated that there are no material differences in the amounts of watersoluble plant food present in soils producing the largest and the smallest crop yields. The figures in the bulletin conclusively show that on a purely physical basis the rich soils do not contain enough water-soluble plant food. to account for all of the mineral matter found in the crop. There is only one alternative, namely, since the figures show that there is not enough water-soluble plant food to account for all that there is present in the crop, it must be derived from other and insoluble forms. In fact, no better evidence could be given showing such a conclusion to be logical than the tables in Bulletin No. 22. In short, the conclusions are entirely at variance with the tables.

Agricultural Experiment Station, St. Anthony Park, Minn.

\section{THE EDISON MEDAL.}

Through the efforts of an organization known as the Edison Medal Association, a fund has been created to establish a medal to be known as the 'Edison Medal,' and the responsibility of annually awarding it has been entrusted to the American Institute of Electrical Engineers.

The Edison Medal Association was founded by the friends and admirers of the great inventor, and in the language of the deed of gift, 'was organized for the purpose of properly recounting and celebrating the achievements of a quarter of a century in the art of electric lighting, with which the name of Thomas Alva Edison is imperishably identified,' and 'for the establishment of an Edison Medal, which should, during centuries to come, serve as an honorable incentive to the youth of America to maintain by their works the high standard of accomplishment by the illustrious man whose name and features shall live while human intelligence continues to inhabit the world.'

The gift was formally made, and the responsibility of conferring it assumed by the institute at its annual dinner given at the Waldorf-Astoria Hotel in New York, on February 11 last, held to not only commemorate the event, but also to celebrate the fiftyseventh anniversary of Mr. Edison's birth.

The fund has been deposited with the Continental Trust Company of New York, and there will be available this year sufficient funds for a medal, which will be awarded by a suitable committee of the institute, soon to be appointed. 